\title{
The Lack and Construction of Teaching Communication in College Sports Teaching
}

\author{
Fei FAN \\ Yunnan Agriculture University Sports Institute \\ Kunming City, Yunnan Province
}

\begin{abstract}
As a basic tool in college sports teaching, teaching communication highlights the dialogues and contacts between teachers and students. It's a good way to improve the effect of sports teaching, and promote the all-round development of students as well. At present, teaching communication is kind of missing in college sports teaching. This paper aims to introduce the phenomenon about how teaching communication lacks in college sports teaching and analyze the reasons, then discuss how to work it out.
\end{abstract}

\section{Keywords: college sports; sports teaching; teaching communication}

Put teaching communication between the teachers and the students first means a lot in today's college sports teaching, which helps teacher better understand how students think and what they need, thus teacher can do some adjustment thus to make their teaching efficiency maximized. For the time being, teaching communication has not attracted much attention yet no matter in the aspect of theory or the aspect of practice. Thus, it needs discussion and deep research, hoping that finally we can find the problem out and figure it out.

\section{The Connotation Of Teaching Communication}

As to teaching communication in college sports teaching, we should first of all get to know the meaning of "communication" and "teaching communication". To educators, "communication" can be explained to: (1) the most essential activity way and the most basic spiritual needs for human being, and see it from a dynamic way, it's the communication and mutual understanding among people; (2) the process when the main bodies of communication affect each other by verbal or non-verbal information; (3) the process people conducted to pass information and share emotion. Communication is the key method to prompt society and human being's development and, no one can develop without communication. While as to "teaching communication", there can be several different ways to describe it from the point of its particularity: (1) take people as the object, people communicate with each other with emotional attitude and valuable information and finally come to the result of education on both sides; (2) take language as the intermediary, teacher and student affect each other by meaningful and valuable communication; (3) take inheriting and spreading culture and human wisdom as the intermediary, communicate with people with information like personal rules of conduct, moral trait, values and emotional experience. We can say that teaching communication belongs to communication but with its own characteristics. It's a specific communication happened among knowledgeable and experienced person. Therefore, to be more specific, as for teaching communication, we can perceive it from these five points: (1) teacher and student are the two main subjects in teaching communication; (2) teaching communication always serve for teaching targets; (3) the function of teaching communication reflected by the educators and the educated exchange information to each other and then make resource shared by each other come true; (4) information, rules of conduct, moral trait, thought, values and social experience are all the main contents of teaching communication; (5) teaching communication has two intermediaries, one is verbal way and the other is non-verbal way.

\section{RATIONAL ANALYSIS TO TEACHING COMMUNICATION IN COLLEGE SPORTS TEACHING}

The communication activity in college sports teaching is differ from the general communication activity, specific differences existed in aspects like the form, subject, mechanism and the carrier.

Firstly from the aspect of communication form, college sports teaching have more various possibilities. For example, communication among single students, between single teacher and single student, between student groups and single teacher and so on, so that teacher and student can communicate with each other through all kinds of ways. See it from the subject of the communication, the most important two subjects, teacher and student, which in college sports teaching, it's for sure that teaching communication existed in such an environment that these two subjects communicate with each other. And only in this way can make this kind of teaching effect to best. As to the carrier, we need firstly make it clear that communication aims to make people understand what the other wants and thinks, then each one can improve themselves gradually. For college sports teaching, this point is also necessary because except for carrier---knowledge on books, communication about things that happened in this society is also very necessary. Teacher and student should establish a unitive and equal relationship, so that each one can speak out loud and thus push education forward. Last but not least, from the mechanism of communication, differ from general social communication in college sports teaching is more precise and objective. Loose and random can only hasten "death".

Based on these characteristics above, in college sports teaching, education on both sides can pass and get the information efficiently, and can have exchange on 
knowledge and emotion, through this everyone no matter teacher or student will all enlarge their view, enrich their knowledge and get more emotion. Therefore, teaching communication is indispensable to college sports teaching, and it has to be emphasized as a fundamental teaching link. However, actually there are still lots of problems existed in college sports teaching and needs to be improved.

\section{ANALysis To THE LACK OF TEACHING COMmunication In COLlege SpoRTs TEACHING AND ITS REASONS}

\section{A. The Lack of Teaching Communication in College Sports Tteaching}

1) Subject turns into object so the communication leans to one side

Obviously, in most cases, teachers in college sports teaching have been regarded as "experienced" and "absolute authority", which means that teacher have absolute status in the class, therefore, teachers teach students and students just listen, for which students' feeling and feedback has been ignored. But as the matter of fact, teaching involves not only teachers but also students, onside-way-of-teaching can only make one of the subject turns into object, and if things go on like this, students will used to get information from teachers but have no feedback, having really bad effect on the communication between the two sides.

2) Communication form becomes easier

Classroom instruction, as a traditional way still taken by nowadays college sports teaching, and that's the communication between single teacher and student group. It's true that this kind of form makes one teacher can communicate with all the students at once, and its efficiency is pretty high, but it can't promise that every single student can have the chance to communicate with their teacher. Therefore, education is lack of pertinence and particularity, so students can't really make progress [1].

3) The carrier and mechanism of communication stick to old ways

In class teaching, subject to text books, majority of teacher trend to pass on fixed knowledge and techniques by a fixed way. Besides, teaching has been misunderstood. It's wrong for people to think that teacher and student equals to leader and stuff, which means teacher set out teaching task, students obey it and just do it. This kind of mode is hard to surpass fixed text book, so the same, it's hard to open both teacher and student's mind. Moreover, it's harmful to student's physical and mental development and think training.

\section{B. Reasons to the Tack of Teaching Communication in College Sports Teaching}

1) Teaching idea and technique of college sports teacher

In the teaching communication of college sports teaching, teacher's teaching ideas have direct effect on its result. Some teachers hold the idea that they are the center of teaching, and they have absolute ability to teach students with their experience and knowledge. As a result, students should abide by what teacher say. Student think and do as teacher say. Then students won't think or do things actively and their ability to develop themselves will be weaken. In addition, some teachers think that teaching itself means teacher teaches and students learn, so if only teacher has taught all the knowledge they should, then they have already done what they supposed to. But they didn't realize that the communication with students is also necessary.

Besides, sports teacher's teaching technique is also of great concern to teaching communication in college sports teaching. At present, most of sports teacher haven't been educated in a professional way, which is also the fault of incomplete relative theory. Hence, sports teachers see they as the center of teaching, only devoting them to teach students relative knowledge and check whether they get it or not by examination. Quite the same with the teaching mode in middle and primary school, teacher and student won't have enough teaching communication.

\section{2) Students'learning style}

Except for teacher, the student is the other main subject, which also plays a key role in sports teaching in college, while most of students obey their teacher without doubt. They have been used to traditional teaching way. Make it clearer, follow the teacher's arrangement and direction; accept information passively without question and communication. Students themselves won't take the initiative to communicate with their teacher. Therefore, it's hard to form a good teaching communication.

\section{3) Teaching contents in college sports teaching}

In general, if the teaching content deserves to explore and has its own values and uncertainty, it's valuable for both teacher and student cultivate their thinking ability and spiritual growth. But the truth is that for many colleges, the teaching contents are all relative basic knowledge. It's all theoretical. Of course it doesn't mean theory is not important, but if only talks about theory, it's not enough. Students don't have room and chance to express what they think, so effective communication is impossible, therefore, teaching communication is also hard to be successful [2].

\section{The Construction Of Teaching COMMUNiCATION In COLlEGE SPORTS TEACHING}

In order to make teaching communication be successful, teacher and student must work together to renew the teaching idea and have more reform and innovation.

\section{A. The Transfer of Orientation towards Educational} Values

Teaching values means people though exist as a student in school, but sooner or later, he has to be one is the society which requires all the teaching activities have to do something with the real world. The transfer here is mainly a transfer in the aspect of goal, put emphasis on cultivate a allround person nit just a person healthy on body [3].

Basically, it reflects on college sports teaching's curriculum view. That's "literal read" to "creative read". The former one is easy to tell. It means know the literal meaning of the text, while the latter one means students get to know 
the real meaning of the text based on their own mind. Obviously, "creative read" better contact sports teaching to real world, which can better reflect and embody the most original and abundant imagery of certain knowledge and technique and its unity to actual problems. Text book is no longer the essential part but just something used to motivate students think and discuss. Students' particularity can then be appreciated, and an open and shared course structure can then be formed. Furthermore, "creative read" don't possess fixed knowledge and technique, students can have their own understanding about the book, and they are encouraged to find out the best way to have connection with the real world with their teacher. Meanwhile, "creative read" don't accept all the fixed knowledge or technique, it may question. So students are required to have their own mind and try to make all the text be used by them. This kind of sports teaching realizes people to be a real people in reality and finally acquire development.

\section{B. Have More Life Vitality in Teaching Rules Establishment}

When we are establishing relative rules, we should take flexible management into consideration. For example, make teaching plan more flexible; sports teacher adopt various forms to conduct teaching activities; have emergent instruction evaluation and so on. Teacher is not the unique leader in the whole process of teaching, and student's status has to be emphasized. Teacher and student have this kind of face to face communication according to certain arrangement. As for the evaluation to teaching, both teacher and student must have self-assessment and mutual-assessment, thus to check the final effect together.

\section{Build up a Free Environment for Communication between Teacher and Student}

Free here refers to in the aspect of mind and in the area of education, which emphasize that both teacher and student are free from the influence of oneself and the outside, expressing points and views freely. Free environment in mind mainly realized by verbal communication and also rely on the innovation and independence of subject's mind. Unfortunately, thought free is quite lack in today's college sports teaching, with teachers just teach and students just listen. To this, we should apply for a kind of teaching mode like "dialogue", which makes the communication among students possible. In another word, teacher and student should be united, both of their role should be accepted and recognized. In the whole process, everyone changes correspondent bad points into good one and then make progress together.

\section{REFERENCE}

[1] Analysis to the lack and construction of teaching communication in college sports teaching [J]. Xinqin. Journal of Changsha Railway University (Social science), 2014(04)

[2] Effective construction of interaction in college sports teaching [J]. Nian Zhongyi. Journal of Henan Educational Institute (Nature science), 2015(05)

[3] Analysis to the lack and construction of teaching communication in college sports teaching $[\mathrm{J}]$.Wang Mingbo. Journal of Hubei Correspondence University. 